\title{
Problem-Based Learning no Ensino de Contabilidade Gerencial: Relato de uma Experiência Brasileira
}

\section{Resumo}

A presente pesquisa teve por objetivo relatar a operacionalização do método PBL em uma disciplina Contabilidade Gerencial no curso de Ciências Contábeis de uma Instituição de Ensino Superior brasileira. A técnica de pesquisa utilizada foi o estudo de caso que envolveu uma abordagem descritiva das aulas de PBL, cujo propósito foi apresentar as propriedades das aulas, a forma de agir e o perfil dos discentes e dos professores. A pesquisa de campo ocorreu em 2013. A coleta de dados é proveniente das entrevistas realizadas com professores, da observação participante e da análise documental. A análise empírica da presente pesquisa teve por alicerce os estudos de Araújo e Arantes (2009), Dochy, Segers, Bossche e Gijbels (2003), Duch, Groh e Allen (2001), MacDonald e Savin-Baden (2004), Ribeiro (2008), Schmidt (1983), Sockalingam e Schimidt (2011), entre outros. Os resultados evidenciam que a integração entre os acadêmicos e as empresas a partir da utilização dos problemas práticos e reais trazidos pelos alunos do ambiente de trabalho proporciona ganhos, tais como: o discente amplia o potencial de resolução de problemas de ordem prática e profissional; e a empresa é beneficiada, tendo em vista que poderá receber, futuramente, profissionais qualificados, aptos à pesquisa e à proposição de solução de problemas. Os professores também ganham, pois são expostos a um ambiente contemporâneo, que proporcionam maior atualização em termos de utilização de conceitos e teorias, devido a sua contextualização. O PBL ajuda a abarcar os estudantes da geração $Y$, tendo em vista que o desejo de participação e comunicação em ambiente interativo com utilização de ferramentas tecnológicas são as grandes marcas dessa geração. Constatou-se que as competências desenvolvidas na abordagem do PBL são similares àquelas exigidas do contador gerencial.

Palavras-chaves: Problem-Based Learning; Contabilidade Gerencial; Competências do Contador Gerencial.

\section{Daiana Bragueto Martins Doutoranda em Controladoria, Contabilidade pela USP e professora da Universidade Estadual de Londrina (UEL). Contato: Rodovia Celso Garcia Cid, PR- $445 \mathrm{Km} 380$, Jardim Portal de Versalhes 1 , Londrina-PR, CEP: 86055-900. E-mail: daianabragueto@usp.br}

\section{Márcia Maria dos Santos} Bortolocci Espejo Doutora em Controladoria, Contabilidade pela USP e professora da Universidade Federal do Paraná (UFPR). Contato: Avenida Prefeito Lothário Meissner, 632, Jardim Botânico, Curitiba-PR, CEP: 80210-170. E-mail: marciabortolocci@ufpr.br

\section{Fábio Frezatti}

Doutora em Controladoria, Contabilidade pela USP e professor Titular da Universidade de São Paulo (USP). Contato: Av. Professor Luciano Gualberto, 908, FEA 3, Butantã, São Paulo-SP, CEP: 05508-900. E-mail: frezatti@usp.br 


\section{Introdução}

O curso de Bacharelado em Ciências Contábeis visa preparar os estudantes para ingressarem no mercado de trabalho, aptos a enfrentar as diversas situações que envolvem as mudanças no cenário político, socioeconômico e cultural. Soares e Araújo (2008) apontam que as exigências legais, sociais e profissionais do contador, ao afetarem a gestão empresarial, exigem que o contador apresente competências que vão além do domínio do conhecimento técnico-científico da área contábil, como a capacidade de solucionar problemas, o exercício do pensamento crítico-reflexivo, a criatividade para identificar os pontos fortes e fracos, a adaptabilidade às mudanças e a autonomia para construir sua própria aprendizagem. A literatura aponta o Problem-Based Learning (PBL) como um método que permite aos estudantes assimilarem as competências (conhecimentos, habilidades e atitudes) necessárias para a conduta profissional contábil de forma significativa em um contexto realista. Porém, essa proposta de inserir na educação contábil não apenas os conhecimentos técnicos necessários, como também as habilidades e as atitudes do profissional exigidas pelo mercado, promove mudanças no processo de ensino aprendizagem.

O PBL é um método de ensino centrado no aluno como sujeito ativo no processo de ensino aprendizagem. É caracterizado pelo uso de problemas reais da sociedade, os quais são contextualizados de forma que o aluno desenvolva o pensamento crítico, as habilidades de solucionar problemas e a aquisição do conhecimento científico e tecnológico sobre o tema pesquisado (Ribeiro, 2008). O PBL permite aos professores do curso de Ciências Contábeis estimularem o aluno a atender às necessidades da sociedade por meio de seus serviços profissionais, pois promove a integração entre a sociedade e a academia ao solucionar, em sala de aula, problemas da prática social (Frezatti \& Silva, 2014), uma vez que a base está centrada nas metodologias educacionais construtivistas, que busca aproximar a teoria da prática e o mercado de trabalho da academia (Ribeiro, 2008).

O principal elemento do método PBL é o ato de tornar o aluno capaz de aprender a aprender, trabalhando em grupos de forma cooperativa na busca de solução para problemas do mundo real. Esses problemas são utilizados para despertar a curiosidade e a iniciativa. O PBL desenvolve no aluno o pensamento crítico e reflexivo e o faz encontrar e utilizar os recursos apropriados para aprender (Duch, Groh \& Allen, 2001). Cabe destacar que, segundo Frezatti e Silva (2014, p. 34), o PBL permite "a aproximação do estudante com a prática, isso, por meio da inserção e intervenção na realidade da área de formação".

Nota-se que a mudança de uma postura passiva para uma aprendizagem centrada nos alunos exige um trabalho de quebra de paradigmas para muitos estudantes e professores. Esses elementos são apontados nas pesquisas de Wood (2003) e Ribeiro (2008). No tocante aos alunos, observa-se que a sobrecarga de informação torna-os inseguros quanto à realização do estudo autodirigido e da seleção da informação útil e relevante, sendo obrigados a caminhar conforme o ritmo do grupo, gerando a possibilidade de não adaptação neste ambiente de aprendizagem autodirigida e colaborativa, devido aos seus diferentes estilos de aprendizagem. Além disso, é exigido do aluno mais tempo de estudos extraclasses. Nesse sentido, faz-se necessário trabalhar o aluno para que ele conheça o método e seus benefícios, de modo que o aluno esteja consciente de como é desenvolvida a aprendizagem cooperativa e o estudo independente e autorregulado.

O papel do professor é alterado no ambiente educacional com o PBL, deixando de ser o detentor do conhecimento ou aquele que controla o aluno e o conhecimento, e de exercer o papel de transmissor de conteúdo como é comum nas aulas expositivas e nas metodologias tradicionais (Dochy, Segers, Bossche \& Gijbels 2003). Ribeiro (2008) afirma que no PBL o professor é visto como o facilitador ou tutor, minimizando o caráter de autoridade e o poder sobre os alunos e sobre o que é necessário aprender, pois não visa à passividade, à transmissão de conteúdos e à memorização, mas, sim, ao diálogo entre professores e alunos, e entre os alunos. Soares e Araújo (2008, p.7) enfatizam que o "PBL não é um método que se adapta a todo professor". Nesta perspectiva, faz-se necessário desconstruir a relação de poder do professor para com os alunos e construir a relação de facilitador. 
Stanley e Marsden (2012) enfatizam que a implantação do PBL é um processo demorado, especialmente na fase de desenvolvimento do PBL, porque é um método novo no ensino de Contabilidade. Por seu caráter inovador, enquanto método de ensino, muitos professores podem optar por não adotá-lo devido ao receio de como proceder neste universo pouco conhecido, optando pela abordagem tradicional, deixando de agregar valor na formação dos alunos (Escrivão Filho \& Ribeiro, 2008; Park, 2006). Diante deste contexto, o objetivo da presente pesquisa está em relatar a aplicabilidade do PBL em um curso de Ciências Contábeis, com o intuito de investigar como é implantado o método na disciplina de Contabilidade Gerencial em Instituição de Ensino Superior (IES) brasileira. Assim, a questão de pesquisa utilizada foi: Como implementar o método de PBL na disciplina de Contabilidade Gerencial em Instituição de Ensino Superior brasileira, proporcionando liberdade de escolhas para os participantes?

A justificativa para a pesquisa está ligada à diversidade de alternativas de aplicação do PBL nas diversas áreas de conhecimentos e nas diferentes IES internacionais e nacionais. Pretende-se contribuir com este estudo para a desmistificação do método de Problem-Based Learning aos professores da área contábil, que, em sua grande maioria, não são licenciados para a docência e tendem a reproduzir os modelos de ensino vivenciados enquanto alunos ou experimentados na prática. Os achados do estudo podem servir como um agente provocador para que essa abordagem ativa de ensino tenha seu efeito multiplicador efetivamente percebido na área de ensino da Contabilidade.

\section{Revisão da Literatura}

\subsection{Fundamentos do PBL}

O PBL foi difundido no mundo em diversas universidades. Inicialmente, aplicado no curso de Medicina, a partir da década de 1960, na McMaster University (Canadá), expandiu-se para a Aalborg University, na Dinamarca (1974); Universiteit Maastricht, na Holanda (1976); Universidade de Linköping, na Suíça (1986); e University of Delaware, nos Estados Unidos da América (1992). No Brasil, o método foi aplicado no curso de Medicina, na Universidade Estadual de Londrina, apenas em 1997, e foi bastante difundido para outras áreas após 2005, com sua implantação na Escola de Artes, Ciências e Humanidades da Universidade de São Paulo (Eachusp), conhecida por USP Leste. A implantação do PBL no curso de Ciências Contábeis ocorreu a partir da década de 1990 com as pesquisas de Johnstone e Biggs (1998), Breton (1999), Milne e McConneell (2001), Hansen (2006), Wilkin e Collier (2009), Pinheiro, Sarrico e Santiago (2011a, 2011b), Manaf, Ishak e Hussin (2011), Stanley e Marsten (2012), entre outras. No Brasil, após 2007, o PBL é abordado no ensino contábil, sendo utilizado apenas em disciplinas isoladas em currículos tradicionais, conforme é evidenciado nas pesquisas de Rodrigues e Araújo (2007), Soares e Araújo (2008), Siqueira, Siqueira-Batista, Morch e Siqueira-Batista (2009), Benjamin Junior e Casa Nova (2012), Frezatti e Silva (2014), Frezatti, Martins, Borinelli e Espejo (2014), Martins, Espejo e Frezatti (2014) e Martins e Espejo (2015).

O PBL é um "método de ensino que fornece aos alunos conhecimentos adequados para a resolução de problemas" (Schmidt, 1983, p. 11). No PBL o problema é utilizado para iniciar o processo de ensino aprendizagem e integrar o ensino aos eventos da vida real. Os pesquisadores Savery (2006) e Hansen (2006) comungam a proposta apresentada por Duch, Groh e Allen (2001, p. 6), na qual os objetivos do PBL são: desenvolver o pensamento crítico e a capacidade de analisar e resolver problemas complexos e reais; encontrar, avaliar e utilizar, apropriadamente, os recursos educativos da aprendizagem; trabalhar cooperativamente em pequenos grupos; demonstrar habilidades comunicacionais; e utilizar os conhecimentos e as habilidades intelectuais adquiridas na universidade para a educação continuada.

Frezatti e Silva (2014) apontam que o PBL é a ponte que aproxima o ensino da prática empresarial, promovendo a formação de profissionais da contabilidade recém-formados mais preocupados com a solução de problemas sociais e proporcionando a integração entre a pesquisa científica e os interesses da população. Dessa forma, reduz-se a distância entre a teoria e a prática no contexto acadêmico (Enemark 
\& Kjaerdam, 2009). O aluno no PBL trabalha em equipe em ambiente de aprendizagem coletiva, colaborativa e cooperativa, com o objetivo de solucionar, com o auxílio de tecnologia e recursos de pesquisas, problemas reais que emergem da sociedade (Araújo \& Arantes, 2009).

O processo de ensino-aprendizagem com PBL é composto, segundo Schmidt (1983), por sete passos: (1) esclarecer os termos e os conceitos não compreendidos; (2) definir o problema; (3) analisar o problema; (4) detalhar as explicações propostas; (5) formular os objetivos de aprendizagem; (6) coletar informações adicionais fora do grupo; (7) integrar os conhecimentos adquiridos com o grupo. Ribeiro (2008) aponta que existem quatro modalidades diferentes de realizar a transição gradual do sistema de ensino convencional para o PBL, podendo ser aplicado em todo o currículo, híbrido, parcial ou post-holding (quando é utilizado pontualmente em determinado momento em disciplinas convencionais). Para Dochy, Segers, Bossche e Gijbels (2003), a metodologia apenas será considerada PBL quando apresentar as seis características a seguir: (1) a aprendizagem é centrada no aluno; (2) a aprendizagem ocorre em pequenos grupos de alunos; (3) os professores são facilitadores ou guias; (4) os problemas direcionam e estimulam a aprendizagem; (5) os problemas são o veículo para o desenvolvimento da prática profissional; e (6) as novas informações são adquiridas por meio da aprendizagem autônoma.

Além disso, o processo de ensino-aprendizagem no PBL é exercido pela união de três elementos fundamentais, sendo eles: o problema, o aluno e o professor. O problema é o elemento central e desencadeia o processo de ensino aprendizagem no PBL (Sockalingam e Schmidt, 2011). O problema no PBL é o material didático e deve ser apresentado por meio de desafios acadêmicos, de cenários ou de problemas reais (Ribeiro, 2008). Nesta abordagem, os discentes precisam apresentar a resolução dos problemas descritos em situações encontradas pelos futuros profissionais em contextos da vida real (Hmelo-Silver, 2004; Sockalingam \& Schimidt, 2011). Além disso, o problema precisa possuir um grau de complexidade, contemplar o conhecimento prévio do aluno, favorecer a interdisciplinaridade e abranger o conteúdo proposto (Ribeiro, 2008). Sockalingam e Schmidt (2011), ao investigarem a percepção dos alunos sobre as características do bom problema em PBL, elencaram onze elementos, os quais foram classificados em duas categorias: recursos e funções. A primeira contempla os elementos do problema (formato do problema, clareza, familiaridade, dificuldade e relevância), e a segunda, além de o bom problema conduzir às questões de aprendizagem, contempla as competências desenvolvidas pelos alunos ao realizarem as atividades acadêmicas por meio de problemas (pensamento crítico, aprendizagem autodirigida, trabalho em equipe, interesse e capacidade de solucionar problemas).

O processo de ensino aprendizagem do PBL tem o aluno como foco e, não, o professor. Os alunos no PBL trabalham em equipes pequenas, em busca da solução do problema, e assumem a responsabilidade pela própria aprendizagem (Schmidt, 1983). Cabe destacar que é bastante evidente a falta de preparo do aluno para realizar pesquisas. O aluno não está habituado a assumir uma postura ativa em sala de aula que promova a construção do conhecimento, que passa a ser visto como um processo de criação no PBL e, não, de repetição. No PBL, o aluno, além de participar do processo de construção do conhecimento, desenvolve habilidades e atitudes exigidas pelo mercado de trabalho no século XXI. As pesquisas de Wood (2003), Ribeiro (2008), Martins e Espejo (2015) apontam que a resistência por parte dos alunos é uma barreira que impede a implantação do PBL.

Um dos grandes desafios do PBL é promover no professor uma nova postura em sala de aula, pois, os professores no PBL assumem, no processo de ensino aprendizagem, o papel de orientadores, tutores, coaprendizes e facilitadores da construção do conhecimento. Ou seja, os professores assumem a função de direcionar os alunos nos estágios do PBL, de acompanhar o processo dos grupos e de promover atividades reflexivas que permitem aos discentes identificarem suas próprias necessidades de aprendizagem. Além disso, os professores trabalham em equipes que incluem outros membros da IES, valorizam o conhecimento prévio dos alunos, buscam encorajar a iniciativa dos alunos, delegam autoridade com responsabilidade aos alunos e não incentivam uma única resposta correta aos problemas (Hmelo-Silver, 2004; Ribeiro, 2008). Porém, nota-se que não é todo professor que se adapta a este cenário menos controlador e com maior desafio conforme apontam as pesquisas de Wood (2003), Ribeiro (2008) e Stanley e Marsten (2012). 
As pesquisas de Wood (2003) e Ribeiro (2008) apresentam várias vantagens e desvantagens desse processo de mudança nos papéis dos alunos e dos professores no PBL. Entre os pontos positivos do PBL, apresentam que o método é centrado no aluno, de modo que estes adquiram conhecimento de forma mais significativa e duradoura, desenvolve habilidade e atitudes desejadas na futura atuação profissional, promove a integração entre diversas disciplinas do currículo, requer que todos os estudantes estejam envolvidos no processo de solução do problema e que utilizem de seus conhecimentos prévios.

Corroborando, o estudo de Enemark e Kjaersdam (2009, p. 18-19) apresenta que o PBL favorece a integração entre os três elementos-chaves na formação dos futuros profissionais, que são a universidade, a empresa e a pesquisa científica. Destaca que os problemas reais orientam a busca por novos conhecimentos e, promovem soluções interdisciplinares, inovadoras e criativas. Os alunos desenvolvem, por meio das atividades em grupos, as habilidades de comunicação e o aprendizado eficaz, ao passo que criam vínculos sociais tanto dentro do ambiente universitário quanto fora. Ribeiro (2008, p.41) completa ao afirmar que, devido ao "trabalho em grupo, há mais comunicação entre os alunos, e estes estabelecem mais parceria entre si, e, nos anos mais avançados, com o corpo docente". A escolha dos membros do grupo ocorre de forma livre, sendo por eles escolhidos, diferentemente da abordagem de Kanet e Barut (2003), em que professores definem os grupos em função de diferentes estilos psicológicos. $\mathrm{O}$ argumento para isso é a legitimação e o fato de que escolheram uma disciplina optativa, um grupo com o qual sabem trabalhar e um tema que consideram interessante e relevante para o grupo. O líder é o integrante do grupo que traz alguma organização para ser o corpo da pesquisa. O secretário é escolhido pelos membros do grupo e tanto o líder como o secretário podem ser alterados ao longo da disciplina, se o grupo assim o desejar.

Por outro lado, entre as desvantagens do PBL, Wood (2003) afirma que há resistência por parte dos professores que não podem exercer diretamente o seu poder e seu papel de detentores do conhecimento, pois diversos professores gostam de transmitir seu próprio conhecimento e compreensão. Assim sendo, não conseguem se adaptar ao papel de facilitador no PBL. Nesta abordagem, é necessário maior recurso humano e investimento na estrutura da instituição, com a realização de gastos suplementares com construção de espaços destinados ao trabalho dos grupos, pois os estudantes necessitam de acesso aos recursos computacionais simultaneamente. Além disso, os estudantes são privados de acesso a um professor particular como ocorre no currículo tradicional, pelo fato de haver sobrecarga de informações, os alunos precisam decidir qual delas é relevante e útil. Muitos alunos se tornam inseguros quanto ao estudo autodirigido e autônomo.

Para os pesquisadores Enemark e Kjaersdam (2009, p. 19), os professores no PBL não precisam decidir o que os alunos devem aprender, mas precisam estar atualizados, visto que os alunos exigem respostas às perguntas sobre novas teorias que encontram na internet ou àquelas que surgem dos estudos autônomos realizados. No PBL, não se sabe quais serão as perguntas dos alunos. Complementando, Ribeiro (2008, p. 42) indica que o PBL "testa os professores de várias formas, por isso devem manter a mente aberta para enfrentar seus desafios", afirmando que "os tutores não conseguem sempre 'saber tudo' e o reconhecimento da necessidade de direcioná-los a outros professores pode ser um fator de estresse psicológico".

De acordo com MacDonald e Savin-Baden (2004), o processo avaliativo no PBL tem por objetivo apoiar a aprendizagem, pois se avalia a capacidade dos futuros profissionais de atuarem em uma situação real do mercado de trabalho e o reconhecimento da necessidade dos aprendizes de adquirirem novas competências. No PBL, utilizam-se diversos avaliadores e diferentes instrumentos de avaliação. Assim, a avaliação acontece pelos próprios alunos, pelos pares, pelos professores e também pela comunidade externa. Cabe destacar que nesta abordagem tanto o professor quanto o método instrucional também são avaliados. Os autores apresentam que nesta abordagem é utilizada uma diversidade de instrumentos avaliativos, a saber: apresentação em grupo e ou individual, planos baseados em casos práticos, portfólio, autoavaliação, avaliação pelos pares, exames orais, diários reflexivos, avaliação do tutor, relatórios, entre outros. 


\subsection{Competências do Contador Gerencial e o PBL}

As competências do contador são exploradas de forma mais ampla na abordagem do PBL do que no processo de ensino-aprendizagem tradicional, pois este abrange somente o conhecimento técnico-científico, e aquela desenvolve, além do conhecimento, as habilidades e as atitudes. Salienta-se que os órgãos reguladores da profissão contábil - o Accounting Education Change Commission (AECC, 1990), a International Federation Accountants (Ifac, 2012), o American Institute of Certified Public Accountants (AICPA, 2005), o Institute of Chartered Accountants (ICA, 2009) enfatizam que a educação contábil deve abordar os conhecimentos, as habilidades e as atitudes necessárias para que os estudantes, ao concluírem a etapa de formação universitária, sejam capazes de atuar no mercado de trabalho.

O método PBL possibilita o desenvolvimento das competências, atendendo tanto às exigências propostas pelos órgãos internacionais quanto pelos órgãos nacionais, apresentadas nas Diretrizes Curriculares Nacionais para o curso de graduação em Ciências Contábeis, por meio da Resolução CNE/CES n. ${ }^{\circ}$ 10/2004. Além disso, permite que os objetivos educacionais propostos na Lei n. ${ }^{\circ} 9.394 / 1996$ sejam contemplados no cenário acadêmico. Destaca-se que os documentos emitidos tanto pelos órgãos internacionais quanto nacionais apresentam as competências essenciais a serem desenvolvidas nas IES para formarem profissionais contábeis capacitados para atuarem no mercado de trabalho.

Corroborando, as pesquisas de Cardoso, Mendonça Neto e Oyadomari (2010) e Cardoso, Riccio, Mendonça Neto e Oyadomari (2010) investigaram as competências do contador gerencial que atua no contexto empresarial brasileiro. Entre as principais habilidades e atitudes que compõem o perfil do contador, destacam-se: pensamento crítico; capacidade de identificar, analisar e resolver problemas; trabalho em equipe; liderança; habilidades comunicacionais; e conhecimento e aplicação dos conteúdos técnicos da prática contábil. Observa-se que estas competências são elencadas por Duch, Groh e Allen (2001), Hansen (2006) e Savery (2006) entre os elementos que compõem os objetivos do PBL.

\section{Design Metodológico}

Esta investigação percorre o caminho da abordagem metodológica quanto ao problema de pesquisa na vertente qualitativa. A pesquisa de campo ocorreu durante os meses de fevereiro a julho de $2013 \mathrm{em}$ ambiente real de sala. As aulas aconteceram normalmente de forma que a rotina pesquisada fosse a real, ou seja, não houve alteração na rotina dos sujeitos envolvidos na disciplina em função da pesquisa realizada, pois se procurou constatar as condições reais de implantação do método PBL em uma disciplina optativa de Contabilidade Gerencial em um curso de graduação de Ciências Contábeis em uma IES pública brasileira. Cabe destacar que esta disciplina teve sua primeira turma em 2011 e, desde a sua concepção, a abordagem metodológica utilizada foi o PBL, sendo a turma de 2013 a terceira com aprendizagem sob este método. A fundamentação teórica sobre a implementação do PBL proporcionou o desenvolvimento das proposições teóricas que orientaram o estudo de caso e estão elencadas na Figura 1. 


\begin{tabular}{lll}
\hline Proposiçães & \multicolumn{1}{c}{ Descrição } & \multicolumn{1}{c}{ Sustentação Teórica } \\
\hline Proposição 1: & $\begin{array}{l}\text { as dificuldades no processo de implantação afetam o } \\
\text { processo de ensino aprendizagem; }\end{array}$ & $\begin{array}{l}\text { Soares e Araújo (2008), Araújo e Arantes } \\
\text { (2009), Ribeiro (2008). }\end{array}$ \\
\hline Proposição 2: & $\begin{array}{l}\text { a participação ativa dos alunos nas aulas de contabilidade } \\
\text { com abordagem em PBL auxilia no desenvolvimento das } \\
\text { competências do contador gerencial; }\end{array}$ & $\begin{array}{l}\text { AECC (1990), AICPA (2005), Soares e } \\
\text { Araújo (2008). }\end{array}$ \\
\hline Proposição 3: & $\begin{array}{l}\text { há traços das metodologias tradicionais nas aulas com o } \\
\text { PBL; }\end{array}$ & $\begin{array}{l}\text { Dochy, Segers, Bossche e Gijbels (2003), } \\
\text { Ribeiro (2008) }\end{array}$ \\
\hline Proposição 4: & $\begin{array}{l}\text { a postura dos professores é diferente da abordagem } \\
\text { tradicional; }\end{array}$ & $\begin{array}{l}\text { Wood (2003), Hmelo-Silver (2004), } \\
\text { Soares e Araújo (2008), Ribeiro (2008). }\end{array}$ \\
\hline Proposição 5: & $\begin{array}{l}\text { o PBL atualiza os professores e os problemas reais levam os os } \\
\text { professores a enfrentarem desafios; }\end{array}$ & $\begin{array}{l}\text { Wood (2003), Enemark e Kjaersdam } \\
\text { (2009), Ribeiro (2008). }\end{array}$ \\
\hline Proposição 6: & $\begin{array}{l}\text { Os objetivos, as características, o processo, os elementos e a a do PBL nas aulas de Contabilidade Gerencial são } \\
\text { distintos de uma abordagem tradicional de ensino; }\end{array}$ & $\begin{array}{l}\text { Schmidt (1983), Duch, Groh e Allen } \\
\text { (2001), Wood (2003), MacDonald \& } \\
\text { Savin-Baden (2004), Hmelo-Silver (2004), } \\
\text { Savery (2006), Hansen (2006), Ribeiro } \\
\text { (2008) e Sockalingam \& Schimidt (2011). }\end{array}$ \\
\hline Proposição 7: & os objetivos do PBL são obtidos ao final da disciplina; e & $\begin{array}{l}\text { Duch, Groh e Allen (2001), Savery (2006), } \\
\text { Hansen (2006), Ribeiro (2008). }\end{array}$ \\
\hline
\end{tabular}

Figura 1. Proposições teóricas

O estudo de caso sobre a disciplina de PBL em Contabilidade Gerencial contou com a direção de dois professores da IES e com a participação efetiva de 38 discentes. Ambos professores são doutores em Contabilidade, sendo que um deles já possuía experiência anterior em docência pela abordagem PBL. Destaca-se que a disciplina aconteceu no período noturno e a maioria dos discentes que a cursaram estavam no último ano do curso e possuíam no máximo 25 anos e apenas $3 \%$ com mais de 35 anos. Neste grupo de estudantes, $82 \%$ estavam empregados. A percepção dos discentes sobre o desenvolvimento dos elementos constitutivos do PBL captou-se por meio do instrumento avaliativo que contempla a autoavaliação, a avaliação pelos pares e a avaliação do método de instrução.

A técnica de pesquisa utilizada foi o estudo de caso único, intrínseco e holístico, que envolveu uma abordagem descritiva das aulas de PBL em contabilidade. Segundo Stake (1995), as situações cotidianas do profissional da educação apresentam-se como possíveis pesquisas que abordam uma sala de aula, tal como a curiosidade por novos procedimentos ou um programa em reforma. No estudo de caso intrínseco e/ou holístico, busca-se entender o ponto de vista das pessoas que estão sendo estudadas, com o intuito de preservar as múltiplas realidades, os diferentes pontos de vista, até mesmo os contraditórios sobre o fenômeno estudado (Stake, 1995). De forma a propiciar a triangulação dos dados, foi possível coletar, por meio de três fontes de evidências, os diferentes pontos de vistas, como o dos professores (entrevistas semiestruturadas); da pesquisadora (observação participante); e dos alunos (análise documental, principalmente, as questões abertas no instrumento avaliativo).

Destaca-se que a entrevista semiestruturada é flexível. Os pesquisadores podem seguir, ou não, o roteiro elaborado e permitir que novas perguntas sejam formuladas no ato da entrevista, bem como a ocorrência de alterações em sua ordem e redação (Bryman, 2012). Com o objetivo de trazer os elementos de adaptação do PBL ao Brasil e à área de Contabilidade, foram realizadas quatro entrevistas com professores que utilizam o PBL em suas aulas. A primeira entrevista ocorreu em abril de 2013, com a professora da Singapore Institute of Management University, que investiga o problema no PBL (entrevistada 1) - realizada no ato de uma visita da professora ao Brasil para conhecer como o método PBL está sendo difundido no país. O entrevistado 2 é pesquisador do PBL no Brasil, trabalhou na implantação do currículo com a abor- 
dagem do PBL na Eachusp e é professor desta IES. A segunda entrevista foi realizada em maio de 2013. A terceira entrevista aconteceu em outubro de 2013, com o professor responsável pela disciplina investigada nesta pesquisa (entrevistado 3), que é doutor em Contabilidade e com experiências prévias na adoção do método. Em novembro de 2013, aconteceu a quarta entrevista com o professor doutor em Contabilidade, que ministrou, pela primeira vez, a disciplina e no momento atuava, também, como coordenador do curso (entrevistado 4). Utilizaram-se os resultados obtidos nas entrevistas, que foram abordados por meio de análise de conteúdo para compreender a operacionalização do PBL em uma disciplina optativa na área de Contabilidade Gerencial, isolada em um currículo convencional de uma IES pública brasileira

Optou-se por realizar a observação participante em sala de aula, pois a participação da pesquisadora ocorreu em todas as aulas da disciplina de forma direta e conhecida pelos discentes. Assim, o risco de ocorrer atividades atípicas por parte dos observados foi eliminada. As observações ocorridas no cenário real da sala de aula foram realizadas durante o primeiro semestre de 2013 com a finalidade de verificar as condições e a execução do PBL em uma disciplina na área de Contabilidade Gerencial.

Entre as fontes de evidência dos dados qualitativos, estão os documentos e os materiais didático-pedagógicos elaborados pelos professores e a pesquisadora para a implantação e execução da disciplina. Bryman (2012) aponta que os documentos utilizados para a coleta de dados precisam estar legíveis, de modo a possibilitar o seu entendimento pelos pesquisadores; não devem ser produzidos especificamente para a proposta da pesquisa; apresentam-se preservados, permitindo a sua análise; e são relevantes aos objetivos do pesquisador social. Os pesquisadores, ao analisar em documentos, precisam compreender o contexto no qual foram escritos e para qual público se destinaram (Yin, 2001).

Os documentos utilizados nesta pesquisa foram: o programa e o plano de aula da disciplina, as apresentações (slides), os relatórios e os materiais produzidos pelos alunos, as listas de presenças e as avaliações acadêmicas. Tais documentos sustentam as experiências do caso em questão e atendem aos quatros critérios de qualidade para utilização da pesquisa documental apresentado por Scott (1990 citado por Bryman, 2012, p. 544), pois os documentos precisam ser autênticos (iguais aos originais), possuir credibilidade (não apresentar distorções ou erros), ser representativos e proporcionar evidências claras e compreensíveis.

Salienta-se que a discussão sobre a operacionalização do PBL no ensino de Contabilidade Gerencial ocorreu por meio da percepção dos professores, dos discentes e da pesquisadora sobre a sua aplicação, em detrimento da opção de avaliar a performance dos estudantes expostos ao PBL, conforme Stanley e Marsden (2012, p. 285).

\section{Análise e Discussão dos Elementos Constitutivos do PBL no Ensino de Contabilidade Gerencial}

\subsection{Estrutura do PBL}

A disciplina Contabilidade Gerencial investigada contempla 32 créditos em 16 encontros de 2 horas aulas por semana e está alinhada ao modelo da USP Leste. De acordo com o Entrevistado 2 e a descrição apresentada por Araújo e Arantes (2009), a presente disciplina utiliza a abordagem da aprendizagem centrada em projetos e baseadas em problemas (Project and Problem-Based Learning).

Destaca-se que o modelo de PBL implantado foi o parcial (Ribeiro, 2008), com diversas intervenções realizadas pelos professores e pela pesquisadora, com abordagens convencionais, tais como as aulas expositivas. O modelo de PBL implantado contempla o trabalho em equipe com um único problema no decorrer do semestre.

Na opinião do Entrevistado 3, professor responsável pela disciplina, é uma vantagem uma disciplina da perspectiva de active learning ser de caráter optativo, pois 
Fragmento 1. Entrevistado 3

...eu acho que esse é o melhor dos mundos. Porque o aluno não está obrigado, ele vai assistir a disciplina porque ele precisa de crédito e aquela disciplina é em um horário viável, ou porque gostou do professor, ou ele acha que o tema é um tema interessante.

Em contrapartida, o Entrevistado 4, afirma que

Fragmento 2. Entrevistado 4

O momento em que a disciplina foi ofertada é o momento em que boa parte dos alunos estão do meio do curso para o final. Então, eu não me convenci de que os alunos estavam totalmente interessados na disciplina pela disciplina, talvez muitos estivessem ali pela necessidade de cumprir créditos.

Experiências evidenciam o impacto do PBL para os alunos, pois, para 100\% dos estudantes, esta foi a primeira experiência com o método, sendo a proposição 1 (as dificuldades no processo de implantação afetam o processo de ensino e aprendizagem) confirmada:

Fragmento 3. Alunos

"Gostei muito da disciplina. Não foi nada do que eu esperava quando me matriculei, no bom sentido! Espero ter outras disciplinas que envolvam tanto os alunos quanto esta"; "Na minha opinião a nova metodologia foi o maior desafio, pois o método tradicional de aprendizagem estava mais enraizado na minha concepção de aprendizagem"; "Acho que a questão de discutirmos e não termos tantas aulas expositivas causaram um certo desconforto no início".

A disciplina em questão teve por objetivo identificar, analisar e solucionar problemas de Contabilidade Gerencial emergentes das empresas brasileiras. Observou-se que, na estrutura de PBL desenvolvida, os alunos buscaram identificar nas empresas, ou seja, em suas experiências profissionais, um problema para trabalhar dentro do tema da disciplina, o qual aborda os impactos dos artefatos e das informações gerenciais sobre a gestão das organizações. Neste sentido, notou-se que os objetivos do PBL propostos por Duch, Groh e Allen (2001) foram alcançados, pois, por meio da estrutura em que o PBL foi desenvolvido na disciplina, na qual a escolha do problema real foi realizada pelos alunos e, não, pelos professores e pela pesquisadora, possibilitou aos discentes, em sua primeira atividade no PBL o desenvolvimento do pensamento crítico e a capacidade de identificar, analisar e resolver problemas complexos e reais, o que vem a apoiar a proposição 2 (a participação ativa dos alunos nas aulas de contabilidade com abordagem em PBL auxilia no desenvolvimento das competências do contador gerencial).

Embora a disciplina de PBL tenha permitido uma forte interdisciplinaridade (Ribeiro, 2008), nesse caso, ela ocorreu de forma autônoma e independente no tocante à integração curricular no curso de Ciências Contábeis. Destaca-se que, se houvesse uma integração com outras disciplinas com abordagem em PBL, reduziria a característica de aula independente e autônoma na matriz curricular do curso de bacharelado em Ciências Contábeis desta IES. O professor responsável pela disciplina ressalta que um dos elementos que influenciam o processo de ensino aprendizagem com o PBL é o seguinte fato:

Fragmento 4. Entrevistado 3

Não sei se eu posso dizer que é uma desvantagem, mas a comparação com outras disciplinas, no sentido de que você não tem uma resposta certa, é algo que precisa ser explicado, pois as pessoas precisam entender essa dimensão e isso não é muito tranquilo. 
O professor relata que a principal característica da disciplina

Fragmento 5. Entrevistado 3

...chama-se contexto. O contexto do aluno, ele passa a fazer parte do aprendizado realmente, já que ele traz um problema que vivencia na empresa, que é relevante para ele. [...] esse aprendizado tem duas partes: o projeto que ele vai desenvolver que tenha certa profundidade e a exposição que ele terá em relação aos projetos dos demais colegas. E, essas duas partes apresentam um diferencial importante na proposta de aprendizagem.

Complementando, afirma que esta disciplina tem por objetivo principal

Fragmento 6. Entrevistado 3

...integrar a experiência do aluno em algo prático e formar um profissional mais pragmático no entendimento de um problema, organizar a solução e, efetivamente, contribuir para essa solução.

Por outro lado, o Entrevistado 4 enfatizou o aprendizado da metodologia em si. Tem-se a expectativa de que o PBL

\section{Fragmento 7. Entrevistado 4}

não ajuda o aluno apenas durante o curso, mas ele é uma metodologia que ajudará o aluno a resolver problemas da vida real, no ambiente profissional dele. Então, a expectativa era que ao final da disciplina o aluno entendesse de forma prática como é que ele pode lidar, principalmente, com os problemas na área de controle gerencial usando as etapas da metodologia. Que o aluno soubesse o que era a metodologia e como aplica-la em situações futuras. Que o aluno seja autônomo para aplicar a metodologia sozinho.

A disciplina seguiu os sete passos apresentados por Schmidt (1983), porém com algumas adaptações. Nas primeiras aulas, fez-se necessário esclarecer os conceitos sobre o tema abordado na disciplina, além de explicar para os alunos o funcionamento do PBL, pois, como já mencionado anteriormente, os discentes que cursaram essa disciplina nunca haviam participado de aulas com essa abordagem. Nesse sentido, a proposição 3 (há traços das metodologias tradicionais nas aulas com o PBL) se faz presente em algumas aulas expositivas, com o intuito de uniformizar a linguagem dos alunos.

Concomitantemente, os estudantes da disciplina definiram o problema a ser trabalhado durante o semestre pelo grupo, o qual foi extraído da realidade em que estão inseridos. O terceiro passo consiste em analisar o problema, ou seja, com base no conhecimento de mundo e nas experiências de vida de cada membro da equipe. Nesse momento, o grupo relata a primeira ideia sobre o problema escolhido, a sua estrutura, o seu contexto e a justificativa pela sua escolha.

A próxima etapa consistiu na elaboração das hipóteses relevantes que possam resolver o problema. Os alunos apresentam o que se sabe e o que não se sabe sobre o tema. Este fato está atrelado ao quinto passo, que é a formulação dos objetivos de aprendizagem. Este elemento precisa ser mais enfatizado na disciplina, de modo que os discentes, ao finalizarem a disciplina, tenham a certeza dos objetivos educacionais desenvolvidos. Na sequência, ocorreu a primeira sessão tutorial na qual os professores e a pesquisadora disponibilizaram algumas referências para os grupos, pois se inicia a fase do estudo independente e autorregulado, em que os discentes buscam informações fora do grupo. Todos os grupos realizaram buscas na literatura e alguns realizaram entrevistas com especialistas dentro e fora das empresas.

No sétimo passo, os alunos discutiram e integraram os conhecimentos individuais por meio do relatório parcial. O conhecimento recém-adquirido e confrontado com o conhecimento prévio foi apresentado para a turma por meio da socialização dos resultados parciais. Correspondeu à apresentação de cada grupo para todos os alunos, com oportunidade de comentários, inicialmente, de um grupo em especial, e depois, de toda a classe e do professor. Assim, os grupos tiveram um tempo para retomar a análise das hipóteses formuladas e a identificação dos fatos. As últimas sessões tutoriais foram destinadas a dis- 
cussão das possíveis soluções do problema. Esta fase também é apresentada na pesquisa de Hmelo-Silver (2004). Dessa forma, constatou-se que o PBL nesta disciplina apresenta um processo bem definido, que foi se construindo no decorrer do curso. Cada aula foi responsável por um dos sete passos apresentados por Schmidt (1983), o qual foi complementado pela proposta de Hmelo-Silver (2004), em que, após a primeira análise, retorna às hipóteses do problema antes de propor uma solução final.

\subsection{Os elementos do PBL: o problema, o aluno e o professor.}

Os elementos fundamentais que direcionam o processo de ensino-aprendizagem no PBL são: o problema, o aluno e o professor. No tocante ao problema, o professor responsável pela disciplina argumenta que o motivo de o aluno escolher o problema nesta disciplina de Contabilidade Gerencial está atrelado ao contexto. O professor responsável pela disciplina relata que

Fragmento 8. Entrevistado 3

a legitimação é o ponto chave da disciplina, pois o aluno optou pela disciplina, ele escolheu o grupo, ele escolheu o tema.

Nessa perspectiva, o aluno também escolheu o problema, ou seja, primeiro se tem o contexto e depois, o problema. Afinal, o propósito da disciplina seria diferente, caso tivesse um problema por aluno, em sala de sessenta alunos. Nesse contexto

Fragmento 9. Entrevistado 3

...a experiência seria igualmente profunda. Do ponto de vista do seu próprio projeto. O que acontece na prática é que se tem a pretensão de tratar o conhecimento, a habilidade e a atitude, e isso proporciona ao grupo uma riqueza muito grande.

Corroborando, o Entrevistado 2 aponta que os princípios desta abordagem estão

Fragmento 10. Entrevistado 2

...na mudança do papel do aluno e do professor em sala de aula, é isso que interessa. [...]E, no vínculo com o real.

O Entrevistado 4 complementa a exposição realizada pelo entrevistado 2, quando afirma que o PBL

Fragmento 11. Entrevistado 4

"tira muito o foco do professor e vai muito para o foco do aluno. Então, assim, uma das grandes vantagens é entender e aceitar que de fato a metodologia permite abordagens diferenciadas das tradicionais"; "ajudar o aluno a resolver problemas da vida real".

Por sua vez, a Entrevistada 1 ressalta que

\section{Fragmento 12. Entrevistada1}

...todas as abordagens de PBL têm o mesmo conceito: aprendizagem para a prosperidade e aprendizagem colaborativa. Levando os alunos a pensar criticamente, sem que haja memorização por repetitividade de conteúdo.

Na sequência, discute-se a presença das seis características, que abordam os três elementos do PBL (problema, aluno e professor), apresentados por Dochy, Segers, Bossche e Gijbels (2003), na disciplina investigada na área de Contabilidade Gerencial. Notou-se que a aprendizagem foi centrada no aluno em aproximadamente $77 \%$ das aulas, seja no processo de resolução do problema ou na apresentação dos re- 
sultados. A aprendizagem ocorreu em pequenos grupos de alunos, que se reuniram todas as aulas para desenvolverem o projeto a fim de encontrarem uma possível solução para o problema. Destaca-se que a turma contemplava a participação de 38 alunos. Foram formados 7 grupos compostos de, no máximo, seis estudantes e sob a orientação dos professores e da pesquisadora.

Assim, evidenciou-se o fato de os professores e de a pesquisadora atuarem como facilitadores ou guias, pois foram parcialmente ministradas cinco aulas expositivas (contemplando menos de $38 \%$ da carga horária da disciplina) com intuito de apresentar o método PBL e os assuntos a serem abordados pelo tema da disciplina. Houve ainda a necessidade de se trabalhar em uma das aulas os conceitos da metodologia científica, tendo em vista a dificuldade apresentada pelos alunos. Porém, ao assumirem o papel de tutores, - professores questionavam os alunos sobre aspectos que eles deveriam estar se perguntando para melhor compreender e gerenciar o problema. Além disso, no decorrer das sessões tutoriais, os professores e a pesquisadora realizaram intervenções e interagiram com os grupos de forma a sintetizar o conhecimento construído a cada aula, e também buscavam uma participação igualitária para todos no decorrer da disciplina. Esse é o espírito da proposição 4 (a postura dos professores é diferente da abordagem tradicional), que exige uma adaptação do professor para conduzir a disciplina. De acordo com o Entrevistado 4, os professores aprendem a utilizar o PBL na prática, ao afirmar que

Fragmento 13. Entrevistado 4

os professores precisam ter a experiência. Foi o que aconteceu comigo, eu só passei a ter motivação de fato quando eu fui até a disciplina e eu pude praticar.

Os alunos valorizaram a participação dos professores e da pesquisadora como um dos aspectos que contribuíram com o processo de ensino aprendizagem, ao relatarem, entre outras coisas, que

Fragmento 14. Alunos

“...foi a primeira disciplina na história do meu curso que houve um acompanhamento mais próximo dos tutores. Houve um estranhamento, um impacto no primeiro momento."; "nas aulas tutoriais foi possível discutir minhas ideias com os colegas e com os professores tendo um feedback mais rápido"; "as discussões entre o grupo nas sessões tutoriais permitiram a troca de conhecimento, e experiências".

Muito embora toda a ênfase da aprendizagem se volte para os alunos, ao serem expostos como facilitadores, os professores e a pesquisadora são estimulados a buscar literaturas específicas para os grupos, que não estavam relacionadas ao seu foco, o que proporcionou condições de atualização de conhecimentos e aumento da assertividade em relação aos conceitos e teorias. Isso ocorreu quando um grupo trouxe questões motivacionais para desenvolver um orçamento.

Além disso, existe um aprendizado por parte dos professores e da pesquisadora ao tratarem os temas de forma contextual e contemporânea. Isso ocorre, por exemplo, em uma situação em que os alunos trazem o contexto de organização que não tem um sistema integrado, e o problema demanda a geração de informações básicas para custos, por exemplo. Dessa maneira, o professor se aproxima tanto do ambiente de ensino quanto do usuário, atualizando-se e ganhando sensibilidade sobre as coisas que ensina, fato este que vem a apoiar a proposição 5 (o PBL atualiza os professores e os problemas reais levam os professores a enfrentarem desafios).

Do mesmo modo, a observação participante possibilitou averiguar que os discentes e os professores assumiram os papéis propostos por Wood (2003), corroborando a proposição 4. Os professores, enquanto tutores, tinham por objetivo incentivar a participação de todos os membros dos grupos; manter o foco do grupo no projeto desenvolvido; avaliar o desempenho; verificar a compreensão dos alunos; e certificar que o grupo alcance os objetivos de aprendizagem. Os professores e a pesquisadora, em todas as aulas, em especial nas aulas das sessões tutoriais, se reuniram com cada grupo por aproximadamente 
15 minutos (100 minutos totais de aula dividido por sete grupos), pois, no PBL, a aprendizagem acontece por meio da reflexão, do diálogo e da troca de experiência entre o professor e o aluno, em que ambos compartilham o processo de construção do conhecimento (Decker \& Bouhuijs, 2009).

Nessa disciplina, observou-se que o problema direcionou e estimulou a aprendizagem, pois os problemas não eram conhecidos pelos alunos e nem pelos professores e pela pesquisadora, e sua solução representou um desafio para ambos. O problema foi o foco de integração da informação de várias disciplinas e direcionou a aprendizagem de pelo menos um conteúdo sobre Contabilidade Gerencial para cada equipe. Além disso, os problemas foram o veículo para o desenvolvimento da prática profissional, pois foram retirados em sua forma original da realidade profissional de sete alunos, que foram considerados os líderes das equipes, que eram também os responsáveis pela integração e desenvolvimento do projeto acadêmico com a empresa. Com respaldo da pesquisa de Ribeiro (2008), trabalhou-se com problemas que necessitam ser solucionados para atender a uma exigência real das organizações; as soluções são potencialmente aplicáveis em seus contextos de origem.

Corroborando os achados de Frezatti e Silva (2014), o processo de encontrar um problema real inserido na realidade empresarial que se enquadrasse no tema da disciplina, elaborar suas hipóteses e buscar o referencial teórico específico foram considerados os elementos mais difíceis para boa parte dos integrantes da disciplina. Fato este comprovado por inúmeros relatos, tais como:

Fragmento 15. Alunos

"o maior problema foi achar o problema"; "escolher um problema real"; "delimitar um problema e as hipóteses"; "encontrar literatura específica sobre o tema”; e

\section{Fragmento 16. Alunos}

... a falta de maturidade acadêmica foi um fator crucial de dificuldade na disciplina. Recortar um problema e transformá-lo em uma pergunta é um processo muito complexo para nós de um curso que foca, principalmente, na capacidade que o aluno tem de interpretar números isoladamente, fora de um contexto econômico e social, como somos 'obrigados' a fazer em uma disciplina com PBL.

A proposição 6 (os objetivos, as características, o processo, os elementos e a avaliação do PBL nas aulas de Contabilidade Gerencial são distintos de uma abordagem tradicional de ensino) tornou-se muito evidente no desenvolvimento da disciplina. Conforme proposta apresentada na pesquisa de Hmelo-Silver (2004), observou-se que a disciplina em PBL proporcionou aos alunos experiências com a resolução de um problema verídico, complexo e extraído do mundo empresarial, corroborando a visão de Duch, Groh e Allen (2001) e Hansen (2006). Observou-se que os alunos absorvem e aplicam melhor os conhecimentos em contexto real. Além disso, notou-se que a cooperação entre todos os membros do grupo se fez necessária para a resolução do problema, tendo em vista que o problema era complexo e que os discentes cursavam, em sua maioria, o último ano e trabalhavam. Esse fato também, é observado na pesquisa de Hansen (2006).

Diversos alunos identificaram uma lacuna no processo de ensino-aprendizagem pela ausência da aplicação de problemas mais simples que fossem apresentados pelos professores e pela pesquisadora para ilustrar aos estudantes a operacionalização do método PBL, antes de atuarem diretamente com um problema extraído da realidade no qual estavam inseridos, afirmativa esta destacada por alguns estudantes, como segue:

Fragmento 17. Alunos

“...acredito que se no início da disciplina houvesse uma apresentação de um trabalho anterior que os professores julgassem como completo, isso nos ajudaria na elaboração do nosso trabalho"; "mostrar um exemplo da aplicação do PBL desde a construção do problema até a solução"; e "exercícios em aula a respeito do PBL". 
O Entrevistado 4 apresenta concordância com a opinião dos alunos, ao passo que sugere aumentar a carga horária da disciplina e trabalhar com

\section{Fragmento 18. Entrevistado 4}

... dois problemas simultâneos, um problema único para toda a sala, que seria o problema-base para o aluno aprender a trabalhar a metodologia, como na medicina, o professor traz o problema e todos os alunos se debruçam e discutem o problema. Eu acho que isso criaria mais interesse porque gera o debate. E, cada grupo vai ter o seu trabalho paralelo que tem que ser concluído até o final da disciplina.

Por fim, notou-se que novas informações foram adquiridas por meio da aprendizagem autônoma, pois os professores disponibilizaram algumas referências aos grupos, de modo que os estudantes tivessem que aprender a partir do seu conhecimento de mundo e de suas experiências acumuladas, em virtude da aprendizagem autodirigida, isto é, os alunos pesquisaram, trabalharam em conjunto, discutiram, compararam, analisaram, compartilharam e debateram o que aprenderam, assim como fazem os profissionais atuantes no mercado de trabalho.

A pesquisa autodirigida na busca de novos conhecimentos e o trabalho autorregulado foram elementos destacados por alguns estudantes como aspectos que contribuíram para a aprendizagem, tais como nas afirmações a seguir:

\section{Fragmento 19. Alunos}

"...um incentivo para sair da zona de conforto por conta da necessidade de pesquisa de material e da socialização dos resultados", "possibilitou enxergar diversas oportunidades de aprendizado e buscar o nosso próprio conhecimento", "relacionar a literatura com os problemas vivenciados no dia-a-dia".

Cabe destacar que a IES disponibilizou todos os recursos necessários para o desenvolvimento das atividades acadêmicas. $\mathrm{O}$ trabalho em equipes foi realizado em sala de aula convencional. $\mathrm{O}$ professor responsável pela disciplina enfatiza que, para o PBL funcionar, bem é necessário

Fragmento 20. Entrevistado 3

...uma estrutura diferente da estrutura tradicional: espaço, local para reuniões, tempo para reuniões, mais pessoas envolvidas. Pois apenas um professor na sala de aula é complicado, depois de um tempo pode até ser simples, mas a princípio não é.

Para o Entrevistado 4, esta foi a sua primeira experiência como professor em uma disciplina com abordagem de PBL e complementa ao relatar que

Fragmento 21. Entrevistado 4

“...essa é uma disciplina que, quando se trabalha com mais de um professor em sala de aula e você tem essa troca de ideias, ela é importante. [...] Então, isso gerou um trabalho muito interessante"; "a ideia do trabalho em conjunto é muito bem-vinda" e “[...]não é muito fácil você operacionalizar isso sozinho dentro de uma disciplina”.

No tocante à participação ativa dos alunos, notou-se, por meio da observação participante, que todos os discentes aprovados na disciplina participaram com mais de $70 \%$ de presença. Porém, um dos elementos que mais prejudicou no desenvolvimento da disciplina foi a não participação integral dos grupos nas aulas concomitantemente, dificultando o direcionamento coerente dos grupos no alcance de seus objetivos. Identificou-se que apenas a figura do líder foi destacada nos grupos e que uma das maiores dificuldades dos alunos foi trabalhar com um grupo permanente durante todas as aulas. Exigiu-se dos alunos 
múltiplas tarefas e, por ter sido a primeira experiência com o PBL, as atividades foram originais e proporcionaram um contínuo aprendizado tanto do problema quanto do PBL para os alunos. Observou-se que, ao final da disciplina, os alunos compreenderam melhor o funcionamento da abordagem do PBL, fato este que proporcionará melhor desempenho do estudante em uma nova experiência com o PBL.

Os estudantes relataram que

Fragmento 22. Alunos

...a sistemática de ter que atuar com um caso real frente a pouca habilidade por nós desenvolvida, pois normalmente estamos atuando no campo da teoria.

Por outro lado, alguns alunos enfatizaram como contribuição à aprendizagem o fato

Fragmento 23. Alunos

...de buscar informações sem que elas sejam fornecidas por um professor.

Compete evidenciar que o estudo e a busca individual pelos conhecimentos, bem como a proximidade com a realidade, foram elementos bastante destacados pelos discentes. O professor responsável pela disciplina evidencia que

Fragmento 24. Entrevistado 3

...o equilíbrio é um aspecto importante para ser encontrado entre os elementos do PBL.

Pois, para ele

Fragmento 25. Entrevistado 3

...o aluno que não está acostumado com a disciplina vai demorar um certo tempo para entender que existem lógicas diferentes. O professor, que de alguma forma tem que correr atrás do material, tem que gerar material para os problemas que vão aparecendo e ele não sabe quais são os problemas. Por outro lado, não pode disponibilizar todo o material, senão o aluno não aprende a pesquisar.

Cabe destacar que o relato do Entrevistado 3 corrobora a confirmação da proposição 5, já apresentada (o PBL atualiza os professores e os problemas reais levam os professores a enfrentarem desafios). Isso é extremamente importante em ambiente em que a formação do professor é custosa, cumulativa e de grande impacto sobre o desenvolvimento do aluno. Além disso, permite, paulatinamente, que o professor possa desempenhar suas atividades por mais de uma perspectiva, o que aumenta seu ecletismo. De qualquer forma, é importante, também, observar o lado do professor, pois o enfoque prático o aproxima das organizações e legitima seu trabalho na área. 


\subsection{O Processo Avaliativo}

Ainda no que se refere à proposição 6 , o processo avaliativo relatado nas entrevistas, conforme apresentado na Figura 2, são complexos e se diferenciam no tocante aos diferentes instrumentos avaliativos, bem como aos objetivos a serem alcançados em cada abordagem.

\begin{tabular}{lll}
\hline \multicolumn{1}{c}{ Entrevistada 1 } & \multicolumn{1}{c}{ Entrevistado 2 } & \multicolumn{1}{c}{ Entrevistado 3 } \\
\hline - Teste de conhecimento; & - Relatório científico parcial e & - Avaliação diagnóstica; \\
- Observação docente; & final; & - Prova individual; \\
- Apresentação individual; e & - Socialização em seminários; & - Relatório parcial e final; \\
- Avaliação reflexiva & - Participação; & - Socialização em seminários parcial e final; \\
- (autoavaliação e avaliação & - Autoavaliação; e & - Autoavaliação; e \\
pelos pares). & - Avaliação pelos pares. & - Avaliação pelos pares. \\
\hline
\end{tabular}

Figura 2. Os instrumentos de avaliação

Com base na experiência da Eachusp, o Entrevistado 2 afirma que

Fragmento 26. Entrevistado 2

...não aplica prova porque, não avalia conteúdo.

Além disso, elencaram-se os instrumentos contidos para avaliar as habilidades e as atitudes, enquanto que na experiência internacional relatada pela Entrevistada 1 os instrumentos de avaliação evidenciados na Figura 2 contemplam três componentes - o conteúdo, a prática e as competências atuais (pensamento crítico, criatividade, trabalho colaborativo, como os alunos trabalham independentemente e a atuação dos líderes e outras funções). Nesta turma de Contabilidade Gerencial, o processo avaliativo foi composto pelos instrumentos apresentados na Figura 2 por meio do relato do Entrevistado 3, os quais foram realizados durante o semestre em diferentes momentos e de forma contínua.

Cabe destacar que os relatórios científicos parciais e finais promoveram o desenvolvimento da habilidade comunicacional de escrita, bem como a aplicação dos conhecimentos de Contabilidade Gerencial e de Metodologia da Pesquisa Científica. Estes instrumentos continham a contextualização do problema, o problema em si, as hipóteses formuladas pelo grupo, o desenvolvimento da pesquisa teórica e a proposta de solução para o problema escolhido.

As apresentações, por sua vez, permitiram desenvolver as habilidades comunicacionais da fala. Os relatórios e as socializações foram utilizados para mensurar, principalmente, as habilidades, pois são os instrumentos avaliativos que evidenciam o resultado do trabalho em equipe, a criatividade, a integração com a empresa e com as demais disciplinas dos cursos, a análise crítica, entre outras. No tocante aos conteúdos, esses instrumentos avaliativos mensuram o domínio do grupo quanto às referências pesquisadas e ao assunto abordado pelo problema da equipe dentro da grande área de Contabilidade Gerencial.

Observou-se, por meio da prova de conhecimento, que aproximadamente $75 \%$ da turma conseguem explicar as tarefas e as estratégias para a solução de problemas, embora apenas $24 \%$ dos estudantes apresentaram quatro dos elementos que representam a importância do método no processo de ensino-aprendizagem. Ao passo que, na seção das questões sobre os projetos desenvolvidos nas equipes, notou-se uma integração entre os membros dos grupos, pois mais de 70\% da turma relataram as principais hipóteses propostas pela sua equipe e apresentaram a relevância do problema pesquisado e os benefícios que a solução de problema pode proporcionar para a empresa de forma coerente. Averiguou-se que aproximadamente $89 \%$ dos estudantes entenderam os papéis dos participantes no PBL; e, em torno de 30\%, confundiram o tema da disciplina com o problema escolhido pelos grupos, além de observarem que uma das principais dificuldades apontadas pela turma foi a identificação do problema. Apenas $27 \%$ da turma relataram de forma correta o processo utilizado na disciplina para selecionar o problema, ratificando, assim, os relatos apresentados pelos alunos. Na sequência, 37\% acertaram a elaboração das hipóteses para um 
novo problema e $47 \%$ descreveram corretamente como seria realizada a pesquisa de campo. No tocante aos conhecimentos de Contabilidade Gerencial, os alunos apresentaram um alto desempenho.

O Entrevistado 3 destaca que, no decorrer do processo avaliativo,

Fragmento 27. Entrevistado 3

os alunos se saem muito bem na apresentação dos projetos e nas recomendações. Isso, para mim, foi muito bom! Uma percepção de orgulho, de mostrar que sabe. Muitas vezes não sabemos dar valor.

Por outro lado, existe a

Fragmento 28. Entrevistado 3

frustração em relação a prova, que nós tentamos entender o que eles aprenderam sobre a técnica. É frustrante, porque eu realmente esperaria um conhecimento maior. Mas isso para mim reflete bem o jeitão da geração.

A avaliação diagnóstica ocorreu antes do início das aulas e apenas 63\% dos estudantes a realizaram. Destaca-se que a execução desta avaliação era facultativa para os alunos, pois ela não estava atrelada à composição da nota do discente para ser aprovado, ou não, na disciplina. Observou-se uma grande preocupação dos discentes no tocante ao elemento "conhecimento", apresentando o professor como o detentor do conhecimento, ou seja, aquele que ministra aulas com objetivo de transmitir o conhecimento (o foco da abordagem tradicional), pois vários estudantes destacaram como perspectiva de aprendizado o fato de

Fragmento 29: Alunos

"adquirir conhecimentos que trabalhem meu perfil como gestor", "adquirir conhecimento de como identificar e solucionar um problema de controle gerencial e que proporcione uma integração dos conhecimentos obtidos no curso até o momento".

Além disso, os alunos também esperavam que os professores

Fragmento 30: Alunos

"dominem os conteúdos curriculares das disciplinas", "passem o conhecimento teórico e prático da área”; "abordem o conteúdo com boa didática e de forma esclarecedora".

Notou-se, também, um despreparo dos alunos perante os pré-requisitos da disciplina, bem como a heterogeneidade da turma e o descomprometimento com a própria aprendizagem de aproximadamente $30 \%$ dos alunos, antes mesmo de a disciplina iniciar, pois, a avaliação diagnóstica antes do processo de instrução visou conhecer o grupo estudantil, bem como direcionar o percurso da disciplina (Silva, 1992).

O instrumento avaliativo realizado na última aula da disciplina capta o ponto de vista dos discentes envolvidos no processo de ensino-aprendizagem sobre as habilidades e as atitudes desenvolvidas no decorrer da disciplina e a sua percepção sobre o método instrucional (PBL). O Entrevistado 3 relata que

Fragmento 31: Entrevistado 3

a autoavaliação e a avaliação pelos pares não é tradição nesta escola, é uma coisa nova. Então, nós implementamos sem muito conhecimento, conhecimento não apenas teórico como também de experiências práticas de alguém que já tenha utilizado.

A autoavaliação e a avaliação pelos pares foram contempladas pelo mesmo instrumento avaliativo, e sua aplicação ocorreu na última aula da disciplina. Este instrumento avaliativo visa coletar o ponto de vista dos discentes sobre o desenvolvimento das habilidades e das atitudes do contador gerencial, bem como a sua opinião sobre o processo de ensino- aprendizagem com o PBL. 
$\mathrm{Na}$ autoavaliação e na avaliação pelos pares, os alunos avaliaram, atribuindo notas de 0 a 10 a si mesmo e aos membros de seu grupo para cada elemento constitutivo das habilidades e das atitudes desenvolvidas na disciplina. Além disso, os alunos possuíam três questões dissertativas que englobavam comentários gerais sobre o funcionamento e o desenvolvimento do grupo; os principais pontos positivos e negativos do trabalho realizado; e o que poderia ser modificado na forma como o grupo trabalhou para promover melhor aprendizagem.

Observa-se no relato a seguir que os objetivos da aprendizagem esperados foram apreendidos pelo conjunto de instrumentos avaliativos.

Fragmento 32: Entrevistado 3

São olhares diferentes; você quer capturar o conhecimento, porque de alguma forma ele é importante. Ele sempre vai ser importante. Porém, as habilidades e as atitudes são possíveis de serem capturas pelo acompanhando do processo, existem alguns subsídios informais ou na avaliação final, como essa que aconteceu nesta turma, que de alguma forma fecha o processo.

Assim, observa-se que, por meio da análise dos instrumentos avaliativos, foi possível identificar os conhecimentos, as habilidades e as atitudes desenvolvidas pelos alunos na disciplina de Contabilidade Gerencial com PBL.

\subsection{As Competências Desenvolvidas}

A proposição 8 (é possível desenvolver as competências do contador gerencial no decorrer da disciplina com abordagem em PBL) foi atingida, pois a disciplina tinha como propósito o desenvolvimento das competências, independente do problema escolhido pelos discentes. No tocante ao conhecimento, observaram-se a apresentação e o desenvolvimento sobre os conteúdos que alicerçam a implantação do método PBL. No que se refere ao conhecimento específico sobre o tema do projeto, observou-se uma complexidade dos problemas trabalhados pelos grupos, fato que exigiu dos alunos o desenvolvimento do pensamento crítico e a realização de pesquisas pontuais sobre os conteúdos do problema que visavam solucionar.

Em relação aos conhecimentos sobre as metodologias e as ferramentas de pesquisa, tinha-se como pressuposto que os alunos buscassem realizar a interdisciplinaridade com os conteúdos expostos na disciplina de metodologia da pesquisa científica, tendo em vista que a interdisciplinaridade é uma das competências enfatizadas pelo Art. $4^{\circ}$ da Resolução CNE/CES n. ${ }^{\circ}$ 10/2004, e que, segundo Araújo e Arantes (2009) e Ribeiro (2008), o PBL proporciona a interdisciplinaridade entre as disciplinas do curso.

E, por fim, foram avaliados os conhecimentos sobre Contabilidade Gerencial, os quais foram brevemente explanados, tendo em vista que os alunos do último ano já cursaram a disciplina de Contabilidade Gerencial, Contabilidade de Custos, entre outras que contemplavam os conhecimentos prévios exigidos como pré-requisito para realizar a disciplina analisada na área de Contabilidade Gerencial. Tal fato corrobora a pesquisa de Cardoso, Mendonça Neto e Oyadomari (2010), ao reportarem as competências técnicas que englobam os conhecimentos específicos da área de Contabilidade Gerencial. Constatou-se que os conhecimentos adquiridos pelos grupos foram divergentes, porém foram bem embasados pelas teorias investigadas pelas equipes.

Notou-se que, em aproximadamente $94 \%$ das aulas, a operacionalização do PBL aconteceu em grupos. Assim, destaca-se que o trabalho em grupo e a comunicação formam as principais habilidades desenvolvidas nesta disciplina. Ressalta-se que, entre as demais habilidades, os estudantes desenvolveram o estudo independente, o trabalho autodirigido, a integração com a empresa e a análise crítica, pois, no período entre as aulas, os alunos precisavam produzir material para serem apresentados aos professores e 
à pesquisadora, exigindo-se, assim, uma alta carga de atividades de pesquisa e trabalho extraclasse. Observou-se que apenas alguns grupos foram capazes de evidenciar uma solução para o problema com clareza e viabilidade. Corroborando, os discentes relataram, por meio da autoavaliação e da avaliação pelos pares, como ponto positivo da abordagem, o desenvolvimento das seguintes habilidades: integração com a empresa e comunicação. Com um pouco menos de ênfase, elencaram a criatividade e a integração com outras disciplinas.

Destaca-se que as habilidades trabalho em equipe, comunicação, resolução de problema e pensamento crítico são competências atribuídas ao contador gerencial (Cardoso, Mendonça Neto \& Oyadomari, 2010; AECC, 1990; AICPA, 2005; ICA, 2009; Ifac, 2012) e se enquadram nos objetivos do PBL (Hansen, 2006; Savery, 2006; Duch, Groh \& Allen, 2001). Destas, apenas trabalho em equipe e pensamento crítico são enfatizadas pela Resolução CNE/CES n. ${ }^{\circ}$ 10/2004, enquanto as outras habilidades abordadas na disciplina, como a integração com a empresa e integração com outras disciplinas, são elencadas somente pela Resolução CNE/CES n.o 10/2004 e pelo ICA (2009).

Por sua vez, entre os aspectos negativos estão a falta de tempo para realizar os estudos independentes, a falta de planejamento do grupo para realizar o trabalho autorregulado, a dificuldade de apresentar uma solução a um problema aberto e, principalmente, a dificuldade dos discentes em trabalhar em grupo. Por outro lado, alguns estudantes evidenciaram que a pesquisa autodirigida em busca de novos conhecimentos e o trabalho autorregulado foram elementos que contribuíram para a aprendizagem. Assim, constatou-se que o PBL proporcionou um crescimento e instigou os estudantes a desenvolverem melhor esses elementos que contemplaram o grupo das habilidades do contador gerencial, principalmente os elementos que englobam a essência do PBL, cuja proposta é que o estudante desenvolva a capacidade de aprender a aprender (learn to learn).

Em relação às atitudes do contador gerencial, observou-se que, para um bom desempenho nesta disciplina, os alunos precisam apresentar empatia, respeito pela opinião dos colegas, comprometimento e possuir experiência profissional. Por sua vez, as atitudes que se destacaram negativamente foram a falta de comprometimento e de liderança por alguns membros dos grupos, fato este que foi crucial para o desenvolvimento do projeto e na obtenção da resolução do problema e, consequentemente, na satisfação do trabatho em equipe. Notou-se que, durante as aulas, as principais atitudes apresentadas pelos discentes foram: a empatia, a colaboração, o interesse e a curiosidade.

A atitude interesse não é evidenciada como uma competência do contador gerencial pela literatura, apenas no tocante ao método. Porém, esta relaciona-se ao fato de o problema estimular interesse nos alunos sobre um determinado tema (Sockalingam \& Schmidt, 2011). Liderança é a atitude mais almejada pelos órgão reguladores (AECC,1990; Resolução CNE/CES n. ${ }^{\circ}$ 10/2004, AICPA, 2005; Ifac, 2012). Nessa perspectiva, cabe enfatizar que a Resolução CNE/CES no 10/2004, apresenta, também, o comprometimento como uma atitude a ser desenvolvida no decorrer dos cursos de bacharelado em Ciências Contábeis.

Pode-se concluir que a disciplina atingiu seu objetivo de integrar ensino, pesquisa e prática (Enemark \& Kjaersdam, 2009), conforme proposição 7 (os objetivos do PBL são obtidos ao final da disciplina), fato este que é observado em um dos relatos avaliativos realizado por um dos discentes sobre a disciplina, ao afirmar que ela

Fragmento 33. Alunos

...permite o exercício da aplicação da teoria à prática vivenciada nas empresas. Mas também é uma disciplina que fornece instrumentos ao pesquisador. Integra estes objetivos, estimula o aluno a desenvolver a análise crítica necessária para ser um profissional mais preparado. 


\section{Considerações Finais e Recomendações}

A presente pesquisa teve por objetivo investigar como foi implantado o método de PBL na disciplina Contabilidade Gerencial no curso de graduação em Ciências Contábeis de uma IES pública brasileira. Evidenciou-se que a implantação do PBL nessa disciplina promoveu um impacto nos estudantes, tendo em vista que para, todos os integrantes da disciplina, esta foi a primeira experiência com uma metodologia de ensino centrada no aluno, e os resultados evidenciaram que os estudantes estavam altamente influenciados pelas metodologias de ensino tradicional. Constataram-se, tanto na observação participante quanto na análise documental, marcas da necessidade do aluno de ter aulas expositivas, com conteúdos ou teoria ministrados pelo professor e de assumir uma posição mais passiva perante a sua própria aquisição e construção do conhecimento. Por sua vez, ficou evidenciada a valorização por parte dos alunos do papel desenvolvido pelos professores e pela pesquisadora como um fator importante que contribuiu no processo de aquisição de conhecimento e desenvolvimento das habilidades e das atitudes propostas.

Verificou-se, também, que o PBL auxilia os alunos a desenvolverem as competências apresentadas nas pesquisas de Cardoso, Mendonça Neto e Oyadomari (2010) e Cardoso, Riccio, Mendonça Neto e Oyadomari (2010), que são necessárias para a atuação do profissional contábil no mercado de trabalho. Nota-se, também, que atende às prerrogativas e os anseios dos órgãos internacionais AECC (1990), Ifac (2012), ICA (2009) e AICPA (2005) e das diretrizes curriculares nacionais apresentadas por meio da Lei n. ${ }^{\circ}$ 9.394/1996 e da Resolução CNE/CSE n. ${ }^{\circ}$ 10/2004, que enfatizam a necessidade de a educação contábil abordar, além dos conteúdos, as habilidades e as atitudes.

Cabe destacar que a metodologia do PBL atinge fortemente os estudantes da geração Y; contempla na formação acadêmica os benefícios proporcionados pela tecnologia de comunicação e informação; permite aos estudantes uma aplicação profissional dessas ferramentas tecnológicas; e incentiva a interação entre os alunos em ambiente educacional que promove a comunicação, a colaboração e a cooperação com o uso de tecnologia aplicada no desenvolvimento de pesquisas.

Devido à mudança de paradigmas em que o professor não pode se utilizar de práticas disciplinares, resta a mudança de postura por parte dos professores, isto é, propor metodologias ativas em que o aluno possa utilizar as suas principais características e ferramentas, o que no PBL acaba sendo o principal elemento na construção do conhecimento. Além disso, proporciona um bom relacionamento entre professores e discentes, gerando um clima de participação espontânea, conforme apontam as pesquisas de Wood (2003), Enemark e Kjaersdam (2009) e Ribeiro (2008), no tocante às vantagens e desvantagens do PBL. Assim sendo, é importante destacar a possibilidade de resistência dos professores e a necessidade de prepará-los por meio de cursos de formação complementares que abordem o PBL.

Dessa forma, os achados desta pesquisa evidenciam a contribuição deste método de ensino para que os professores consigam se comunicar com os estudantes contemporâneos, minimizando conflitos de gerações que, por vezes, ocorrem na abordagem tradicional. Aos estudantes, significa uma oportunidade de aprender de forma significativa, aliando a teoria à prática, de forma a capacitá-los para o mercado de trabalho por meio do desenvolvimento de suas diversas competências (conhecimento, habilidades e atitudes). Aos gestores acadêmicos, representa o desafio de refletir e promover mudanças significativas no âmbito do processo de ensino-aprendizagem dos cursos sob sua tutela que possam abordar o PBL.

Entre as limitações do presente estudo, estão a percepção dos participantes envolvidos no ambiente de sala de aula que contemplou a aplicação do PBL na disciplina Contabilidade Gerencial na turma de 2013. Outro aspecto que pode ser entendido como limitação foi o fato de que os alunos participantes da disciplina já estão em fase avançada do curso, o que proporciona o enfoque de liberdade de escolha. Por outro lado, têm-se alunos já com uma visão do que o curso pode proporcionar, ao passo que estes se encontram em um momento de busca por trabalho, com menor interesse no curso. Sugere-se que futuras pesquisas sejam realizadas para investigar as principais vantagens e desvantagens do PBL em relação a outras abordagens de ensino-aprendizagem nas disciplinas da área de Contabilidade Gerencial, bem como, pesquisar por meio de um estudo longitudinal a evolução no PBL na educação contábil. 


\section{Referências}

Accounting Education Change Commission (AECC). (1990). Objectives of education for accountants: position and issue statement number one. Issues in Accounting Education, 5(2), pp. 307-312. Recuperado em 7 novembro, 2013 de http://www2.aaahq.org/aecc/pdf/position/pos1.pdf

American Institute of Certified Public Accountants (AICPA). (2005) Personal Competencies. Ney York. Recuperado em 7 novembro, 2013 de http://www.aicpa.org/InterestAreas/AccountingEducation/ Resources/DownloadableDocuments/Personal\%20Competencies.docx

Araújo, U. F. \& Arantes, V. A. (2009). Comunidade, conhecimento e resolução de problemas: o projeto acadêmico da USP Leste. In U. F. Araújo \& G. Sastre (Orgs.). Aprendizagem baseada em problemas no ensino superior. (pp. 101-122). São Paulo: Summus.

Benjamin Junior, V., \& Casa Nova, S. P. C. (2012). Teoria da complexidade e contabilidade: estudo da utilização da aprendizagem baseada em problemas como abordagem complexa no ensino de contabilidade. Anais Congresso USP de Controladoria e Contabilidade, São Paulo, SP, Brasil, 12. Recuperado em 24 julho, 2014 de http://www.congressousp.fipecafi.org/artigos122012/719.pdf.

Brasil. Lei no 9.394, de 20 de dezembro de 1996. Estabelece as diretrizes e bases da educação nacional. Diário Oficial [da] República Federativa do Brasil. Brasília, DF, 23 dez. 1996.

Brasil. Resolução CNE/CES nº 10, de 16 de dezembro de 2004. Institui as Diretrizes Curriculares Nacionais para o Curso de Graduação em Ciências Contábeis, bacharelado, e dá outras providências. Diário Oficial [da] República Federativa do Brasil. Conselho Nacional de Educação. Câmara de Educação Superior. Brasília, DF, 28 dez. 2004.

Breton, G. (1999). Some empirical evidence on the superiority of the problem-based learning (PBL) method. Accounting Education: an International Journal, 8(1), pp. 1-12. doi.org/10.1080/096392899331008

Bryman, A. (2012). Social research methods. 4th ed. New York: Oxford University Press.

Cardoso, R. L., Mendonça Neto, O. R. \& Oyadomari, J. C. (2010). Os Estudos internacionais de competências e os conhecimentos, habilidades e atitudes do contador gerencial brasileiro: análises e reflexões. Brazilian Business Review, 7(3), pp.91-113. Recuperado em 24 julho, 2014 de http://www. spell.org.br/documentos/download/7818

Cardoso, R. L.; Riccio, E. L.; Mendonça Neto, O. R. \& Oyadomari, J. C. (2010). Entendendo e explorando as competências do contador gerencial: uma análise feita pelos profissionais. Advances in Scientific and Applied Accounting, 3(3), pp. 353-371. Recuperado em 24 julho, 2014 de http://www.atena.org. $\mathrm{br} /$ revista/ojs-2.2.3-06/index.php/ASAA/article/view/ 1778

Decker, I. R., \& Bouhuijs, P. A. J. (2009). Aprendizagem baseada em problemas e metodologia da problematização: identificando e analisando continuidades e descontinuidades nos processos de ensino aprendizagem. In U. F. Araújo \& G. Sastre (Orgs.). Aprendizagem baseada em problemas no ensino superior. (pp. 177-2014). São Paulo: Summus.

Dochy, F., Segers, M., Bossche, P., \& Gijbels, D. (2003). Effects of problem-based learning: a meta-analysis. Learning and Instruction, 13, pp. 533-568. doi.org/10.1016/S0959-4752(02)00025-7

Duch, B. J., Groh, S. E., \& Allen, D. E. (2001). Why problem-based learning? A case study of institutional change in undergraduate education. In B. J. Duch, S. E. Groh, \& D. E. Allen. The power of problem-based learning: a practical "how to" for teaching undergraduate courses in any discipline. (pp. 3 -12). Virginia: Stylus Publishing.

Enemark, S. \& Kjaersdam, F. (2009). A ABP na teoria e na prática: a experiência de Aalborg na inovação do projeto no ensino universitário. In U. F. Araújo \& G. Sastre (Orgs.). Aprendizagem baseada em problemas no ensino superior. (pp. 17-42). São Paulo: Summus. 
Escrivão Filho, E., \& Ribeiro, L. R. C. (2008). Inovando no ensino de administração: uma experiência com a Aprendizagem Baseada em Problemas (PBL). Cadernos EBAPE, número especial, (pp. 1-9). Recuperado em 24 julho, 2014 de http://www.scielo.br/pdf/cebape/v6nspe/v6nspea04.pdf

Frezatti, F.; Silva, S. C. (2014). Prática versus incerteza: como gerenciar o estudante nessa tensão na implementação de disciplina sob o prisma do PBL? Revista Universo Contábil, 10, pp.28-46. doi. org/10.4270/ruc.2014102

Frezatti, F., Martins, D. B., Borinelli, M. L., \& Espejo, M. M. S. B. (2014) Análise do desempenho de alunos na perspectiva do CHA em disciplina utilizando PBL: o que significa a síntese? Anais Congresso USP de Controladoria e Contabilidade, São Paulo, SP, Brasil, 14. Recuperado em 24 julho, 2014 de http://www.congressousp.fipecafi.org/web/ artigos142014/375.pdf

Hansen, J. D. (2006). Using problem-based learning in accounting, Journal of Education for Business, 81(4), pp. 221-224. doi.org/10.3200/JOEB.81.4.221-224

Hmelo-Silver, C. E. (2004, September). Problem-based learning: what and how do students learn? Education Psychology Review, 16(3), pp. 235-266. doi.org/10.1023/B:EDPR.0000034022.16470.f3

Institute Of Chartered Accountants (ICA). (2009). Professional Accreditation Guidelines for Higher Education Programs. October, Australia. Recuperado em 7 novembro, 2013 de http://kecheng.lut.cn/ upload/20110502/2011050212335826.pdf

Internation Federation of Accountants (IFAC). (2012). Proposed International Education Standard (IES) 3: initial professional development - professional skills (revised). Exposure Draft. August. New York: International Accounting Education Standards Board (IAESB). Recuperado em 7 novembro, 2013 de https://www.ifac.org/publications-resources/ies-3-initial-professional-development-professional-skills-revised.

Johnstone, K. M, \& Biggs, S. F. (1998). Problem-Based learning: introduction, analysis and accounting curricula implications. Journal of Accounting Education, 5(3/4), pp.407-427. doi.org/10.1016/S07485751(98)00026-8.

Kanet, J. J.\& Barut, M. (2003). Problem-Based Learning for Production and Operations Management. Decision Sciences Journal of Innovative Education, 1(1), pp. 99-118. doi.org/10.1111/1540-5915.00007

MacDonald, R. \& Savin-Baden, M. (2004). A briefing on assessment in problem-based learning. LTSN Generic Centre, Series n. 13. Recuperado em 24 janeiro, 2015 de https://www.heacademy.ac.uk/sites/ default/files/id349_a_briefing_on_assessment_in_problembased_learning.pdf

Manaf, N. A. A., Ishak, Z., \& Hussin, W. N. W. (2011). Application of problem-based learning (PBL) in a course on financial accounting principles . Malaysian Journal of Learning and Instruction. 8, pp.21-47. Recuperado em 24 janeiro, 2015 de http://mjli.uum.edu.my/images/pdf/8mjli/mjli82application.pdf

Martins, D. B., \& Espejo, M. M. S. B. (2015). Problem Based Learning - PBL no ensino de contabilidade: guia orientativo para professores e estudantes da nova geração. São Paulo: Atlas.

Martins, D. B., Espejo, M. M. S. B., \& Frezatti, F. (2014) Avaliação de habilidades e de atitudes em abordagem de problem based learning no ensino de controle gerencial. Anais do Congresso da Associação Nacional de Programas de Pós-Graduação em Ciências Contábeis, Rio de Janeiro, RJ, Brasil, VIII. Recuperado em 24 janeiro, 2015 de http://congressos.anpcont.org.br/congressos-antigos/viii/ images/74_39c94.pdf?201504291 14417

Milne, M. J., \& McConnell, P. J. (2001). Problem-based learning: a pedagogy for using case material in accounting education. Accounting Education: An International Journal, 10(1), pp.61-82. doi. org/10.1080/09639280122712

Park, S H. (2006). Impact of Problem-Based Learning (PBL) on teachers' beliefs regarding technology use. Tese de doutorado em Filosofia, Faculty of Purdue University, West Lafayette, Indiana 
Pinheiro, M. M., Sarrico, C. S. \& Santiago, R. A. (2011a). Competências de autodesenvolvimento e metodologias PBL num curso de contabilidade: perspectivas de alunos, docentes, diplomados e empregadores. Revista Lusófona de Educação, 17, pp.147-166. Recuperado em 13 outubro, 2013 de http:// www.scielo.mec.pt/pdf/rle/n17/n17a10.pdf

Pinheiro, M. M., Sarrico, C. S. \& Santiago, R. A. (2011b, set./dez.). Como os acadêmicos se adaptam a um ensino baseado em PBL numa licenciatura tradicional em contabilidade. Revista de Contabilidade e Organizações. 5(13), pp.109-131. Recuperado em 13 outubro, 2013 de http://www.rco.usp. br/index.php/rco/article/view/321

Ribeiro, L. R. C. (2008). Aprendizagem baseada em problemas (PBL): uma experiência no ensino superior. São Carlos: EdUFSCar.

Rodrigues, E. A., \& Araújo, A. M. P. (2007). O ensino da contabilidade: aplicação do método PBL nas disciplinas de contabilidade em uma instituição de ensino superior particular. Revista de Educação, 10(10), pp.166-176. Recuperado em 13 outubro, 2013 de http://www.pgsskroton.com.br/seer/ index.php/educ/article/view/2150/2047

Savery, J. R. (2006). Overview of problem-based learning: definitions and distinctions. Interdisciplinary Journal of Problem-based Learning. 1(1), pp.9-20. doi.org/10.7771/1541-5015.1002.

Schmidt, H. G. (1983). Problem-based learning: rationale and descriptions. Medical Education, 17, pp.1116. doi.org/10.1111/j.1365-2923.1983.tb01086.x

Silva, C. S. (1992). Medidas de avaliação em educação. Petrópolis: Vozes.

Siqueira, J. R. M., Siqueira-Batista, R., Morch, R. B., \& Siqueira-Batista, R. (2009, jul./set.). Aprendizagem baseada em problemas: o que os médicos podem ensinar aos contadores. Revista Contabilidade Vista \& Revista, 20(3), pp.101-125. Recuperado em 13 outubro, 2013 de http://revistas.face.ufmg.br/ index.php/contabilidadevistaerevista/article/view/652/ 420

Soares, M. A., \& Araújo, A. M. P. (2008). Aplicação do método de ensino Problem-Based Learning (PBL) no curso de Ciências Contábeis: um estudo empírico. Anais do Congresso da Associação Nacional de Programas de Pós-Graduação em Ciências Contábeis, Salvador, BA, Brasil, 2. Recuperado em 13 outubro, 2012 de https://www.furb.br/especiais/download/879756-215326/epc\%20045\%20-\%20 index3.php.pdf.

Sockalingam, N., \& Schmidt, H. G. (2011, spring). Characteristics of problems for problem-based learning: the students' perspective. Interdisciplinary Journal of Problem-based Learning, 5(1), pp.6-33. doi.org/10.7771/1541-5015.1135.

Stake, R. E. (1995). The art of case study research. New York: Sage Publication, Inc.

Stanley, T., \& Marsden, S. (2012). Problem-based learning: does accounting education need it? Journal of Accounting Education, 30, pp.267-289. doi.org/10.1016/j.jaccedu.2012.08.005.

Wilkin, C. L., \& Collier, P. A. (2009). A problem-based approach to accounting education: A pragmatic appraisal of a technologically enabled solution. International Journal of Education and Development using Information and Communication Technology (IJEDICT), 5(2), pp.49-6. Recuperado em 14 agosto, $2013 \mathrm{de}$ http://ijedict.dec.uwi.edu/viewarticle.php?id=658\&layout=html

Wood, D. F. (2003). ABC of learning and teaching in medicine: problem-based learning British Medical Journal (BMJ), 326, pp.328-330. doi.org/10.1136/bmj.326.7384.328

Yin, R. K. (2001). Estudo de caso: planejamento e métodos. Porto Alegre: Bookman. 